\title{
Improving psychosocial services for vulnerable families with young children: strengthening links between health and social services in Germany
}

\author{
(C) (1) $\Theta$ OPEN ACCESS
}

Ilona Renner and colleagues describe cross-sectoral collaborative efforts in Germany to enhance the skills of parents to care for young children

\author{
Ilona Renner research manager ${ }^{1}$, Victoria Saint independent consultant ${ }^{2}$, Anna Neumann \\ researcher ${ }^{1}$, Daria Ukhova independent consultant ${ }^{3}$, Sabine Horstmann consultant ${ }^{4}$, Ullirich Boettinger \\ coordinator $^{5}$, Martina Dreibus coordinator ${ }^{6}$, Astrid Kerl-Wienecke coordinator ${ }^{7}$, Pilar Wulff \\ coordinator $^{8}$, Paul Mechthild head ${ }^{1}$, Heidrun Thaiss director ${ }^{9}$ \\ ${ }^{1}$ National Centre for Early Prevention, Federal Centre for Health Education, Koeln, Germany; ${ }^{2}$ Berlin, Germany; ${ }^{3}$ Berlin, Germany; ${ }^{4}$ Koeln, Germany; \\ ${ }^{5}$ Early Childhood Intervention, Ortenau, Germany; ${ }^{6}$ Early Childhood Intervention, Federal State Rhineland Palatinate, Germany; ${ }^{7}$ Early Childhood \\ Intervention, Frankfurt am Main, Germany; ${ }^{8}$ Early Childhood Intervention, Dortmund, Germany; ${ }^{9}$ Federal Centre for Health Education, Koeln, Germany
}

In Germany, a priority within health and social care for over a decade has been improving parents' interactions with and care for their children. This was in response to a large study in 2007 of children's health and development ${ }^{1}$ that identified $20 \%$ of children aged 3 to 17 years were at risk of a mental health disorder. ${ }^{2}$ Furthermore, gaps in the child protection system were becoming obvious, with high profile cases of child neglect leading to public demand for urgent action. Burdened families were slipping through the net of social support and welfare and being driven towards susceptibility to negligent parenting and in worst cases child maltreatment.

Low socioeconomic status is closely linked to poor child health and development outcomes, as well as increased risk of adverse experiences in early childhood. ${ }^{34}$ For example, in Germany, $26.0 \%$ of children living in families of low socioeconomic status show symptoms of mental health problems, compared with $9.7 \%$ of children in families with high socioeconomic status. ${ }^{5}$ Poverty is associated with a broad range of psychosocial burdens, including early parenthood and parental adverse childhood experiences. 6 These problems might lead to lower parental capabilities, potentially acting as mediators for children's poorer health and development, as well as higher risk for maltreatment.

Germany's Early Childhood Intervention (ECI) programme, implemented in 2006, supports the goal of providing equal opportunities for all children to develop their full potential. Subsequent expansion has been driven by the increasing proportion of children living in families receiving social benefits, rising from $12.5 \%$ in 2011 to $14.6 \%$ in 2017. ${ }^{7}$ Despite overall prosperity and strong economic growth in Germany, the need for ECI is greater than ever.

The German programme (Frühe Hilfen) comprises prevention oriented, voluntary psychosocial services offered to all pregnant women and families with a child aged 0-3 years, with additional support for those in difficult circumstances. This approach is aligned with the evidence based Nurturing Care for Early Childhood Development Framework, launched during the 71st World Health Assembly in May 2018. ${ }^{8}$

One major challenge to improving psychosocial care for families is the "prevention dilemma"; voluntary preventive services are used more by families with a lower level of need than by those who would benefit more. To overcome this challenge cross-sectoral collaboration is needed, especially between health and social services sectors. In Germany the use of social welfare services, and especially child and youth welfare services, is often highly stigmatised, as it can be seen to acknowledge or expose parental deficits. In contrast, healthcare services are highly valued: nearly all children, $98 \%$, are born in a maternity clinic $^{10}$ and $99 \%$ attend regular well-child visits in a paediatric practice. ${ }^{11}$ This creates a valuable opportunity to identify and 
deal with the psychosocial needs of pregnant women and parents of young children in a sensitive and non-stigmatising way and refer them to adequate support measures in the child and youth welfare sector.

We describe Germany's ECI programme and implementation between 2006 and 2017, analyse the factors enabling cross-sectoral collaboration to achieve programme goals and objectives, and examine the opportunities and challenges inherent in this collaboration. This case study was developed according to a methods guide produced by WHO Partnership for Maternal, Newborn and Child Health. ${ }^{12}$ Methods included reviewing available data, interviewing 21 key informants from four municipalities, producing a working paper, and holding a stakeholder workshop to review the working paper and gather additional inputs (see supplement 1 on bmj.com).

\section{Programme description}

Germany's ECI programme established municipal cross-sectoral collaborative networks across the country as well as developing and implementing diverse voluntary psychosocial measures. Although most municipalities provided some preventive measures to support families with young children before the programme, systematic cooperation between the health sector and the child and youth welfare sector was often lacking. ${ }^{13}$

Following a pilot phase between 2006 and 2011, ${ }^{14}$ scale-up ran from 2012 to 2017; the federal ECI programme is now operating at scale and in a consolidation phase (fig 1). In January 2018, with the establishment of the Federal Foundation for Early Childhood Intervention, federal funding for ECI became mandatory, with all municipalities eligible to apply for financial support to further develop their ECI networks and measures. Since 2012, the federal government has committed around $€ 51 \mathrm{~m}$ ( $£ 45 \mathrm{~m} ; \$ 59 \mathrm{~m}$ ) a year to bolster funding provided by federal states and municipalities.

The National Centre for Early Prevention (NZFH) was established by the Federal Ministry for Family Affairs, Senior Citizens, Women, and Youth in 2007 to steer and provide technical monitoring and support for the ECI programme. NZFH is hosted by the Federal Centre for Health Education and works in collaboration with the German Youth Institute.

Germany's federalist structure is a diverse cluster of shared and divided legislative power and managerial responsibilities across the national level, 16 federal states, and about 600 municipalities (supplement 2 on bmj.com). The ECI programme therefore requires collaboration at all three administrative levels to ensure that all relevant services provided by the health sector, the social services sector, and others are networked as effectively as possible (box 1).

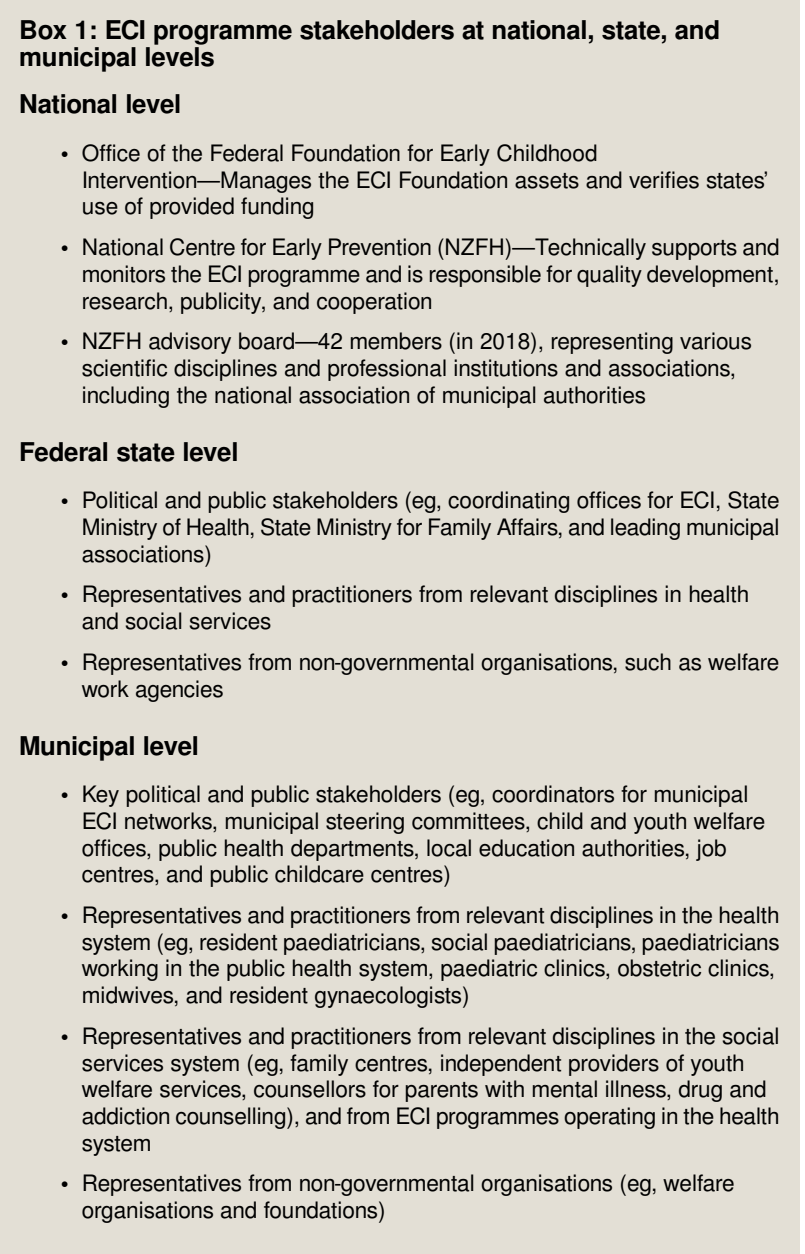

The ECI programme offers services to all pregnant women and families with young children and additional psychosocial support services to families in need, an estimated $13 \%$ of young families ${ }^{15}$ and about 300000 children aged $0-3$ years (box 2). Use of ECI measures is voluntary, and there is no screening to identify families in need as this could contribute to further stigmatisation of the target group. Other programmes and services exist for the relatively small number of cases (1-2\% of families) in most need of support-that is, families for which state intervention or control is mandatory, including the possibility that the child is taken into care. Box 2: Risk inventory to identify families in need of psychosocial
support in Germany

The risk inventory is based on a systematic review of national and international long-term developmental studies and systematic reviews. ${ }^{16-18}$ Four or more of the following risk factors-experienced by $12.9 \%$ of German families with children aged 0-3 years-indicates the need for additional support to prevent adverse health outcomes or maltreatment:

- Single parent

- Unplanned pregnancy

- Infant regulatory problems related to sleep, feeding, or crying

- High parental stress

- High parental impulsivity or explosiveness

- Intimate partner violence (current or former)

- Symptoms of parental anxiety or depressive disorder

- Parental adverse childhood experiences

- Frequent conflicts in the current romantic relationship

- Young mother (<21 years at birth of the child)

- Poverty (family receiving social benefits)

ECI networks in each municipality design and implement services to fit with and respond to specific local circumstances 
and community needs, within a country-wide framework that supports the institutionalisation of quality standards, professional training and qualification, and accountability, with the ultimate goal of ensuring fast and effective services for families (box 3; suppl 3 on bmj.com).

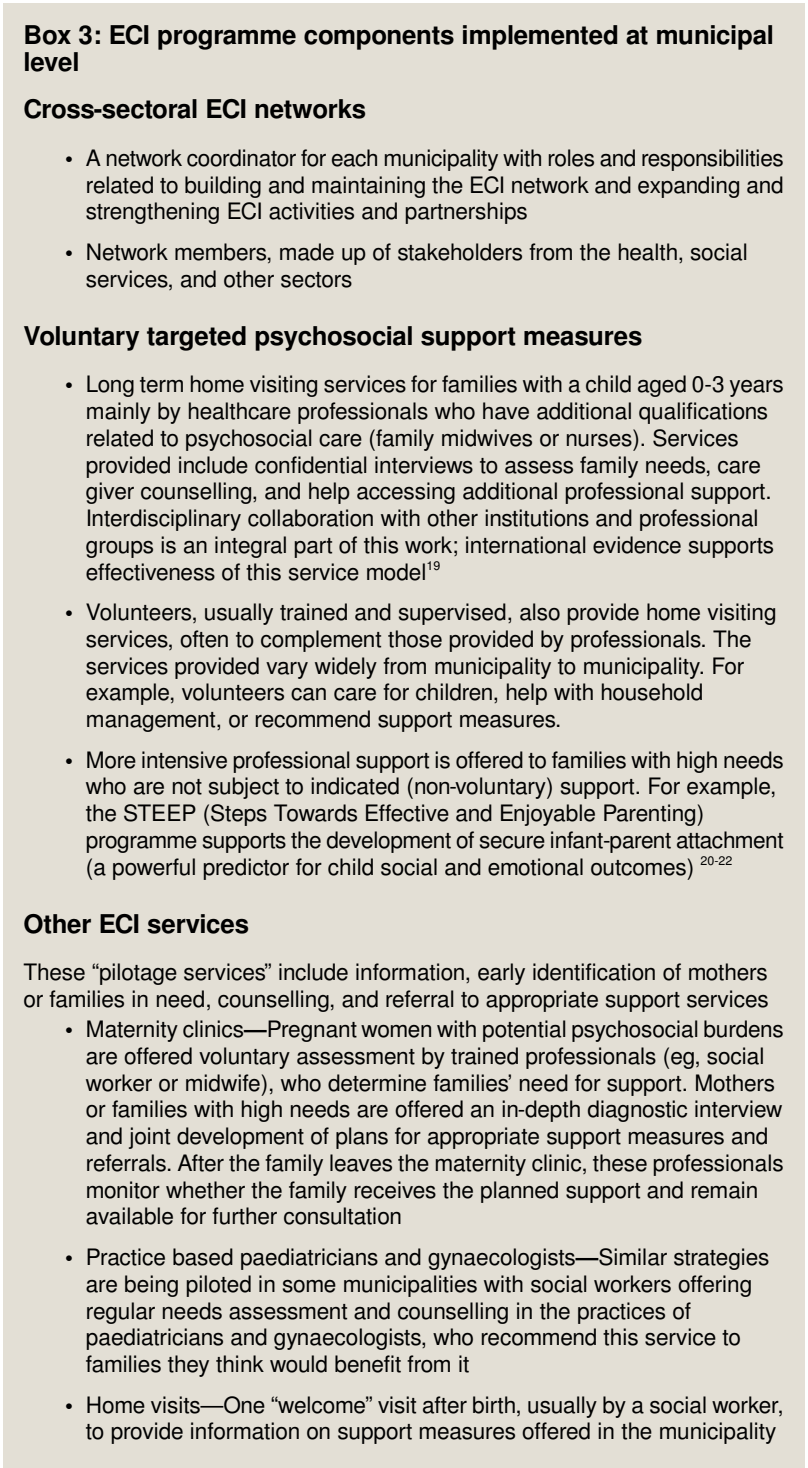

\section{Progress towards implementation objectives}

The ECI programme is based on four steps to achieve effective outcomes, which also underpins NZFH's research framework:

- Cross-sectoral networks and support measures are implemented in all municipalities

- Families in need make use of ECI support measures

- ECI support measures are assessed positively by target group

- ECI support measures are effective at enhancing families' competencies

During the scale-up phase from January 2013 to December 2017, progress on each of these steps was monitored at the federal level using various methodological approaches (box 4). NZFH collaborated closely with research institutions and universities to ensure methodological standards and critical assessment of research to identify achievements and areas where progress could be accelerated, and to tackle the challenges faced in evaluating complex interventions. ${ }^{23}$

Box 4: Monitoring progress during 2013-17, selected examples

- Municipal surveys in 2013 and 2015 focused on the structural development and expansion of the $\mathrm{ECl}$ programme and collecting data from network coordinators, who are mainly situated in the social services sector but some are in public health authorities

- From 2013 to 2015 an observational longitudinal study was conducted to estimate the effectiveness of long term home visits on parental capabilities $(n=937)$

- A nationwide representative study from 2014 to 2015 involving more than 8000 mothers and fathers with a child aged 0-3 aimed to gain insights into the psychosocial stressors in families in Germany, how often they occur, associated (contextual) variables, and the extent to which families from different social groups use the professional support currently available, including $\mathrm{ECl}$ measures

- In 2015, 1019 mothers, selected from a register based random sample, were interviewed to explore their perceptions of, and satisfaction with, the ECl support provided by (family) midwives and nurses

- In 2016, a research cycle was launched to systematically monitor how maternity clinics $(n=383)$ and paediatricians $(n=815)$ and gynaecologists (data collection ongoing in 2018) with their own practices cooperate with the social services sector. Research questions concern both the intensity and quality of case related cross-sectoral cooperation. Baseline investigations (mixed method design combining quantitative and qualitative data collection) were carried out from 2017 to 2018, and representative surveys will be conducted at regular intervals for trend analyses.

Table 1 shows some examples of the results of these studies in relation to progress towards nationwide implementation. Survey results also pointed to areas in need of improvement. For example, in the 2015 municipal survey, $36.8 \%$ of respondents said their municipal ECI network needed to be further developed, and 53\% said the ECI home visiting services in their municipality were insufficient (because of a shortage of professionals, especially midwifes and nurses).

Study results indicate that families in need are better reached and have higher uptake of the services targeted towards them than of services offered universally. Both groups assess the ECI services positively, which is critical given all use of ECI services is voluntary (box 5). 
Box 5: Progress towards ECl's objectives with examples

\section{Families in need make use of $\mathrm{ECl}$ support measures}

In a 2014-15 survey among 8063 families with children aged 0-3 years, 13\% indicated they received or had received long term home visits by a family midwife or nurse and $1.4 \%$ received or had received visits by a volunteer.6 Families receiving social welfare benefits were more likely to receive long term visits from a family midwife or nurse $(17.8 \%$ of families receiving social welfare benefits $v 11.7 \%$ of families not in receipt of benefits). In contrast, the families receiving social welfare benefits had much lower uptake of universal support measures than those receiving no social welfare payments, (eg, prenatal classes $34.1 \%$ v. $67.1 \%$; midwifery care up to 8 weeks after birth $74.0 \%$ v $90.3 \%$; medical services for mothers after birth (courses teaching postpartum exercises, etc) $27.4 \% \vee 64.7 \%$ ).

$\mathrm{ECl}$ support measures are assessed positively by target group

In a 2015 survey of 1019 mothers, 618 had used long term home visits by a midwife or nurse ${ }^{28} 92.6 \%$ of the 148 women visited by a family midwife or nurse rated it positive or very positive and $94.3 \%$ of the 770 who had been visited by midwife nurse without family training. $90.1 \%$ of women receiving social benefits rated the visits as positive or very positive $(n=204)$ and $95.7 \%$ of women not receiving social benefits $(n=414)$. These results show that the visits are highly valued by the target group of vulnerable families. Most women would recommend the services to another family $(98.7 \%$ for family midwife or nurse and $97.9 \%$ for midwife or nurse).

$\mathrm{ECl}$ support measures are effective with respect to enhancement of families' competencies

Long term home visits by health professionals (nurses) have been adopted by the German ECl programme because of convincing national and international evidence that they are effective. ${ }^{19} 29$ The home visitation programme "nobody slips through the net" was tested in 2007-2011 in ECI pilot projects ${ }^{30}$ and showed improved social development of children compared with those in the control group. ${ }^{31}$ Mothers judged their 1 year olds' character as "less difficult" and the mother-child interactions in the intervention group were less "dysfunctional" than those in the control group. The home visitation programme "Pro Kind" showed a tendency for positive treatment effects on infant cognitive development at 6 and 12 months as well as improved parental capabilities at 12 months compared with controls. ${ }^{32} \mathrm{~A}$ longitudinal observational study conducted by NZFH in 2013-2015 with 937 families receiving home visits by health professionals showed increased parental capabilities in five domains. $^{33}$

Although families in need are more likely to be supported by a family midwife or nurse than less vulnerable families, the difference in use is still not as big as might be expected, given this service is designed for parents with high psychosocial burdens. Strategies to improve access for vulnerable families might include training for health professionals in sensitive interviewing and need assessment. Vulnerable families also need more opportunities to participate in the design of support measures.

\section{Critical factors for cross-sectoral collaboration}

The ECI programme operates within Germany's decentralised structure of federal, state, and municipal levels and is affected by the challenges facing the health and social services sectors (box 6). These include human and financial resource constraints and substantial variation across the country in capacity to respond to population needs. Within this context, we discuss the factors at federal and municipal level, as well as interprofessionally, that supported implementation and operationalisation of cross-sectoral collaboration within the ECI programme.
Box 6: Strengths, opportunities, and challenges of Germany's federalised structural context for the $\mathrm{ECl}$ programme

In Germany's decentralised system, federal states and municipal authorities have autonomy to design and develop their ECI networks, services, and initiatives, including those specifically related to cross-sectoral collaboration. This flexibility enables a high degree of responsiveness to diverse and dynamic local conditions and needs. It also fosters local stakeholder ownership and empowerment.

The ECl programme, however, must try to implement and guarantee coordination, and a degree of standardisation and coherence, both horizontally between the two sectors at each level as well as vertically across the three federal levels. It can be complex and time-consuming to coordinate with and find agreement across the many stakeholders and representative agencies. Furthermore, federal level instruments (eg, guidelines, initiatives) are subsequently interpreted and operationalised at state and then municipal level, which may differ in terms of their legislative and bureaucratic structures, service provisions, and the individual and institutional vested stakeholders.

Concerns related to confidentiality, data protection, and information sharing can be an additional challenge for cross-sectoral collaboration between professionals for families. While the Federal Child Protection Law provided a greater degree of certainty on such issues, separate and changing codes of law continue to pose problems, and the EU-wide General Data Protection Regulation that came into effect in May 2018 may have increased concerns again.

Considerable demographic and socioeconomic diversity across states and municipalities in Germany influence the population needs and the availability of human, financial, and infrastructural capacity and resources to respond. Insufficient human resources in both the health and social services are a widely acknowledged challenge, affecting the ability and willingness of staff and agencies to implement initiatives and to engage in the cross-sectoral networks specifically.

\section{New national structures, new legislation, and increased federal funding}

Sustained high level political commitment to ECI since 2006 resulted in the enactment of new legislation and increased public financing, which together enabled the shift from pilot to scale-up phase, including fostering cross-sectoral collaboration.

The government's decision to establish a new centre with a clear mandate proved instrumental to translating Germany's aspiring new ECI approach into reality. Working in the areas of quality development, research, advocacy, and cooperation, the NZFH has contributed to increased visibility and prioritisation of ECI in both public and political domains, and to greater formalisation and systematisation of ECI in Germany. The NZFH's multisectoral, multistakeholder, multilevel advisory board has fostered a stronger integration of science and practice and provided important legitimacy, critical oversight, and steerage. For example, the 2009 definition of ECI described the conceptual breadth and complexity of this newly established field of action, which resulted in heterogeneous psychosocial services being offered and cooperation structures. The subsequent 2014 mission statement provided guidance to all professionals in ECI, establishing common understanding. ${ }^{34}$

From 2007 to 2008, a systematic legal framework began to be established, with federal state laws on child health and welfare. Collaboration across sectors was instituted as a basic structure within these laws in some federal states (eg, Saarland, Schleswig-Holstein, Rhineland Palatinate). Germany's Federal Child Protection Act (Bundeskinderschutzgesetz) came into force on 1 January 2012. The experiences of professionals and the results of scientific monitoring of the ECI programme pilots were taken into account during its design.

The act institutionalised comprehensive approaches for ECI and child protection in Germany, as distinct but related concepts firmly centred on child protection as well as prevention. It created new powers for those working for children's wellbeing, with a major objective the strengthening of structural networking and cross-sectoral cooperation. The act acknowledged that responsibility for child wellbeing spans widely across family, 
state, and society, contributing to a shift in perspective and commitment by many stakeholders. In particular, it helped to close gaps and clarify the roles, responsibilities, and intersections between health and social services sectors, and supported orientation towards families rather than the goals of institutions or sectors.

Implementation of the act led to increased, more stable, funding arrangements. Municipalities can apply for additional resources specifically to fund cross-sectoral activities (eg, employing ECI network coordinators and staff for pilotage services). Application for funding contains flexibility to allow for adaptation to local needs and contexts (supplement 4).

Although the act's value is widely acknowledged, challenges remain. The legislation was primarily developed by, and through the lens of, the social services rather than health sector. ${ }^{35}$ Some innovative efforts are underway, particularly at state and municipal level, to reinforce ECI in health legislation, and to strengthen engagement of health authorities. For example, in Berlin the "Babylotsen" scheme (box 8) in maternity clinics is funded by the Berlin Senate Department of Health, Care, and Equality. In the state of North Rhine-Westphalia, research into a pilot project for social workers to work within doctors' practices is being funded by the German Innovation Fund of the Federal Joint Committee, (decision-making body of the joint self-government of physicians, dentists, hospitals, and health insurance funds in Germany).

Box 8: Examples of how the ECl programme has fostered cross-sectoral innovation and best practices

Interprofessional Quality Circles (IQCS) involve health and social services professionals meeting regularly to discuss anonymised cases and develop strategies for individual cases ${ }^{36}$ This fosters reciprocal understanding, which directly benefits the practitioners' day-to-day work. These circles were initiated by NZFH and the Association of Statutory Health Insurance Physicians of the Federal State Baden-Württemberg, and are led by doctors in collaboration with professionals from the social services sector at municipal level. IQCs have been tested and adopted by other states, including North Rhine Westfalia, and are being considered by others.

Pilotage services in maternity clinics (Lotsensysteme) were first implemented in North Rhine Westphalia in 2006, followed in 2007 by "Babylotse" in Hamburg. These and similar models of a service for identifying, counselling, and referring mothers and families to appropriate support measures postnatally were adopted and implemented in maternity clinics in other federal states and municipalities. In $2017,28.9 \%$ of 383 maternity clinics that responded to a survey (sent to $n=673$ clinics with more than 300 births a year, response rate $56.9 \%$ ) offered this service to mothers with newborn babies. ${ }^{37}$ These services are well accepted by the target group. An evaluation at Charité

Universitätsmedizin Berlin showed that in 2013 only $2.5 \%$ of 1050 mothers identified as psychosocially burdened declined the offer of an in-depth interview with a Babylotse. In Dortmund, the one clinic out of four that implemented a pilotage service experienced a rapid increase in the number of births.

ECl quality dialogues started in 2018 and are an example of ongoing efforts to improve quality. 24 municipalities seized the opportunity to jointly identify challenges in their $\mathrm{ECl}$ policies-for example, concerning the participation of families or extending municipal collaboration beyond the health and social services sectors. The process will be evaluated and the results published and shared with other municipalities.

\section{Flexible, cross-sectoral implementation architecture at municipal level}

A great strength of the programme is that it allows for flexible implementation at municipal level, anchored around the municipal cross-sectoral networks. This enables innovation to local needs and contexts and a strong sense of local empowerment and ownership. It has also resulted in considerable diversity throughout the country in the implementation and funding of municipal networks (box 7).
Box 7: Examples of diverse implementation and funding at state and municipal levels

\section{Frankfurt am Main, State of Hessen}

The ECI network has a declaration specifying the network's structure, partners, and mandate. Collaboration includes information sharing, coordination on structural components, and operational issues, including to address challenges related to issues such as data security. Smaller sub-networks for specific geographical areas in the city facilitate the specific cross-sectoral collaboration needed to ensure that families can access $\mathrm{ECl}$ services in their day-to-day social context. The linkages between $\mathrm{ECl}$ and child protection services are strengthened through regular meetings between the respective networks for $\mathrm{ECl}$ and child protection via a working group on "Children's rights" in place since 2008. The ECI network in Frankfurt am Main has been able to leverage significant additional funding from well-resourced local charitable foundations that are entrusted to direct finances for population benefit.

\section{Ortenau, Offenburg, State of Baden-Württemberg}

A municipality-wide $\mathrm{ECl}$ steering group with the most important stakeholders aims to ensure equal standards throughout the municipality. This is complemented by ECl "competence centres" throughout the district which provide direct and coordinated psychosocial care, and sub-municipal "round tables" of relevant actors. Through federal, municipal, and other funding sources, the $\mathrm{ECl}$ network in Ortenau directly funds services based on cross-sectoral collaboration (eg, providing new parents with information about and support to access $\mathrm{ECl}$ and other services), which is not the case in all municipalities. A key outcome has been that families in need are identified and provided services much earlier with these structures in place - previously support was often only offered when it was in fact too late to prevent problems. Local evaluation found that $79 \%$ of all 600 families using the $\mathrm{ECl}$ system were reached very early (during pregnancy until the first birthday of the child), most of these shortly after birth.

These networks built on local existing conditions, partnerships, and needs. The regular exchange between municipal ECI networks (horizontally) and between municipal, state, and federal level (vertically) creates channels for sharing experiences, innovations, and lessons. This has supported the identification of successful local initiatives, which have then been rolled out in other areas or nationwide (box 8). This "learning by doing" approach was vital in the development of an operational knowledge base for the ECI programme.

\section{Building capacity and generating interprofessional benefits}

Capacity building and generating clear benefits for stakeholders have been critical for the implementation of the ECI programme and especially its vision for cross-sectoral collaboration.

The programme has engendered a shared understanding and a sense of common responsibility between stakeholders, and clarified the intersections and boundaries between their respective roles and responsibilities. The definitions and guidelines developed collaboratively by federal, state, and municipal stakeholders have laid out critical milestones in this evolution over the past 11 years. Capacities and skills for cross-sectoral collaboration have also been progressively developed among professionals, gradually bringing them out of their separate boxes. ${ }^{252638}$ As one network member from Frankfurt am Main said: "We consider ourselves as one unit: as a family, not as an individual service provider."

We noted increasing appreciation by professionals of the inherent value of cross-sectoral collaboration. A survey in 2016-17 among maternity clinics and paediatricians showed that health professionals felt increasing pressure to care for families with high needs, perceiving this as a severe challenge. Of the 815 paediatricians who responded (23.1\% response rate), $77 \%$ said they "perceive ECI as a relief for their work," as it would help them identify and provide optimal support for families beyond medical care. ${ }^{37}$

ECI professionals recognise this as supporting a shift towards a more holistic and family centred approach, as reflected in initiatives such as the Interprofessional Quality Circles (box 8). 
Programme evaluation and stakeholder perspectives show that the success of formal mechanisms for cross-sectoral collaboration also depends on more informal and interpersonal efforts by network members. The formally established and funded municipal network coordinators serve as important boundary spanners, enabling and strengthening cross-sectoral collaboration. Their success depends largely on their informal brokerage and trust building. Likewise, partners view the interpersonal aspects of the municipal cross-sectoral networks as important. Network members also appreciate being able to discuss new or emerging issues in the network meetings and with other members, including outside the formal meetings. These interactions are an important way of sustaining and strengthening engagement between practitioners.

\section{Lessons for the future}

Several key lessons for enabling cross-sectoral collaboration can be drawn from our analysis. Firstly, the mutually reinforcing nature of structural and governance frameworks is critically important. Structural frameworks act as the collaboration's skeleton, but interprofessional and personal relationships make programme objectives achievable by empowering stakeholders and creating shared understanding and commitment, mutual trust, and respect, and thus strong social connectivity.

The importance of the people who drive cross-sectoral collaboration cannot be overstated. These people have essential roles as champions, bridge builders, and boundary spanners. ${ }^{39}$ They find creative and innovative ways to shift and cross the sectoral, administrative, professional, and institutional boundaries to respond to the needs of stakeholders and beneficiaries. Given this vital role, ensuring their continuing presence, commitment, and active engagement is essential for programme sustainability.

\section{"Joint agreements take their time, but in the end this results in thorough satisfaction of all partners." Network member, Dortmund, April 2018}

The process of establishing frameworks, together with professional understanding, capacities, and relationships, is often slow, and not a linear process. Different strategies can be used to foster and enhance collaboration across sectors and levels, using a mix of formal mechanisms (eg, working groups and standards), as well as capitalising on and strengthening interprofessional benefits. This can include fostering a working culture where professionals feel comfortable trusting each other and asking for support or advice.

The wider structural context can offer powerful means through which to mandate or foster cross-sectoral collaboration, but also presents challenges. In Germany, legislative mandates and stable funding for cross-sectoral collaboration provided certainty, which increased network influence in municipal contexts and attracted stakeholder commitment. However, the structural challenges of health and social services sectors strongly affect ECI generally, and specifically cross-sectoral collaboration.

Human resource constraints in both sectors are especially problematic. Half of ECI network coordinators reported that the number of professionals employed for home visiting services were insufficient to meet municipality needs. ${ }^{27}$ The shortage of midwives and nurses in general, and with specialist ECI training, generates strong competition for employment. Some ECI trained professionals move back to standard midwifery or nursing, which is better paid. Workplace pressure for all stakeholders may also act as a disincentive, discouraging people from working cross-sectorally or engaging in the networks.
Germany's success in involving health professionals in ECI networks seems at least partly due to a convergence between the progressive establishment of the collaborative structures and the increasing and changing population needs. Professionals could therefore see direct benefits of cross-sectoral collaboration for their work. Better ways to incentivise or enable health insurers to support ECI activities, including payment mechanisms for work spanning traditional sectoral boundaries, also need to be identified.

A strength of the ECI model is the high level of municipal autonomy enabling local adaptation. However, municipalities differ considerably in their overall economic, demographic, and social profiles and in their commitment and capacity to support ECI. Better measurement and evaluation of these equity dimensions and expanding the role of beneficiaries as active participants in the programme could further strengthen Germany's ECI programme.

A challenge for Germany's ECI framework and many municipalities might be to include more sectors in the multisectoral approach-for example, early childhood education services (eg, nursery and day care) and the labour market sector. This could strengthen service design and responsiveness and enable the programme to better account for and tackle other factors and social determinants relevant to child and family health and wellbeing.

The $€ 51 \mathrm{~m}$ annual federal funding secured by the Federal Child Protection Act in 2012 may not be sufficient. The funding does not take account of inflation and must be distributed to around 600 municipalities. Moreover, the proportion of vulnerable families in need of early psychosocial support is expected to continue to increase. In 2017, the total number of births increased for the fifth consecutive year, and this trend is expected to continue. This dovetails with increased needs from recent high levels of inward migration, including of refugees, many of whom are young and may be traumatised, and other immigrants with low socioeconomic status.

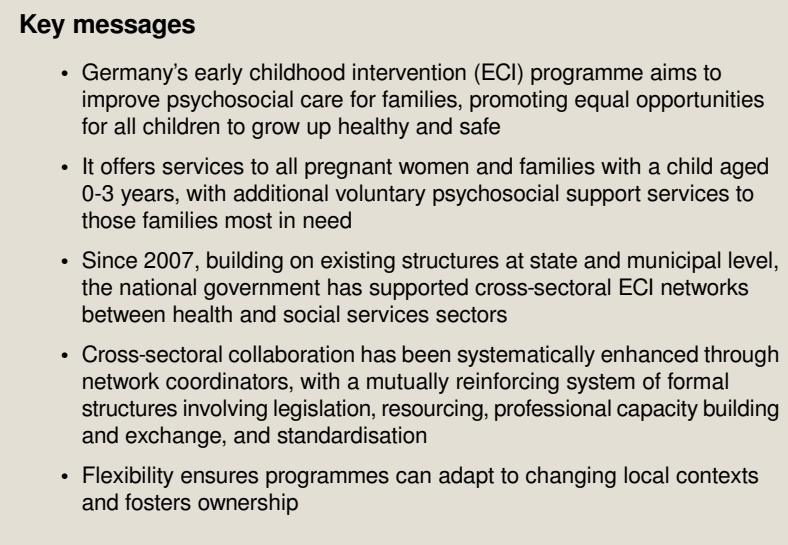

See www.bmj.com/multisectoral-collaboration for other articles in the series. We thank all ECl programme collaborators, past and present, and those who have participated in this case study process, including Thomas Fischbach, Claudia Hellmers, Georg Kaesehagen-Schwehn, Christine Klapp, Joanne McManus, Dörte Podratz, Alexandra Sann, Gabriele Trost-Brinkhues, and Stephanie Wilhelm.

Contributors and sources:This article is based on findings from a review of the cross-sectoral collaborative work of NZFH, commissioned by the PMNCH Secretariat (hosted by WHO) and to which all authors contributed. IR, VS, AN, and DU conceptualized and drafted the first version, with input from SH. IR and VS revised it and produced subsequent drafts, including to incorporate feedback from UB, MD, AKW, PW, MP, and HT. For the review supporting the findings of this 
article VS drafted the working report based on NZFH and programme materials prepared by IR and AN and key inputs from DU, UB, MD, AKW, PW, and MP; SH undertook key informant interviews and summarised their findings. IR is the guarantor.

Competing interests: We have read and understood BMJ policy on declaration of interests and declare funding from the PMNCH Secretariat (VS, DU, SH) for consultancy fees and related costs for undertaking the case study. IR, AN, and MP are salaried employees for BZgA who were paid to design, implement, and monitor the programme. HT is director of BZgA, which is an agency of the German Federal Government. UB, MD, AKW, and PW are salaried employees of state and municipal authorities to implement and manage the programme in their respective geographical areas.

Provenance and peer review: Commissioned; externally peer reviewed.

This article is part of a series proposed by the Partnership for Maternal, Newborn and Child Health (PMNCH) hosted by the World Health Organization and commissioned by The BMJ, which peer reviewed, edited, and made the decision to publish the article. Open access fees for the series are funded by $\mathrm{PMNCH}$.

1 Die Studie zur Gesundheit von Kindern und Jugendlichen in Deutschland (KiGGS). Results of the KiGGS [Study on the health of children and adolescents in Germany] baseline study. https://www.kiggs-studie.de/english/results/kiggs-baseline-study.html.

2 Hölling H, Schlack R, Petermann F, Ravens-Sieberer U, Mauz E. KiGGS Study Group Psychische Auffälligkeiten und psychosoziale Beeinträchtigungen bei Kindern und Jugendlichen im Alter von 3 bis 17 Jahren in Deutschland - Prävalenz und zeitliche Trends zu 2 Erhebungszeitpunkten (2003-2006 und 2009-2012) Ergebnisse der KiGGS-Studie - Erste Folgebefragung (KiGGS Welle 1) [Psychopathological problems and psychosocial impairment in children and adolescents aged 3-17 years in the German population: prevalence and time trends at two measurement points (2003-2006 and 2009-2012): results of the KiGGS study: first follow-up (KiGGS Wave 1)].Bundesgesundheitsbl. 2014;57:807-1910.1007/s00103-014-1979-3

3 Letourneau NL, Duffett-Leger L, Levac L, Watson B, Young-Morris C. Socioeconomic status and child development: a meta-analysis. J Emot Behav Disord 2013;21:211-24. 10.1177/1063426611421007

4 Reiss F. Socioeconomic inequalities and mental health problems in children and adolescents: a systematic review. Soc Sci Med 2013;90:24-31

10.1016/.j.socscimed.2013.04.026 23746605

5 Kuntz B, Rattay P, Poethko-Müller C, Thamm R, Hölling H, Lampert T. Social inequalities in health of children and adolescents in Germany. Results of the cross-sectional KiGGS Wave 2 study. Journal of Health Monitoring 2018;3:17-33. 10.17886/RKI-GBE-2018-083 6 Salzmann D, Lorenz S, Sann A, et al. Wie geht es Familien mit Kleinkindern in Deutschland? In: Datenreport Frühe Hilfen. [How are families with small children in Germany?] ECI Data Report Aug 2017. 2018:6-23. https://www.fruehehilfen.de/fileadmin/ user upload/fruehehilfen.de/pdf/Publikation-NZFH-Datenreport-Fruehe-Hilfen-2017.pdf

7 Seils E, Baumann H, Höhne J. Kinder Im SGB II-Bezug. Eine Auswertung aktueller Daten der Bundesagentur für Arbeit. Policy Brief No 15. Wirtschafts- und Sozialwissenschaftliches Institut der Hans-Böckler-Stiftung (WSI), 2017. https://www.boeckler.de/pdf/p_wsi_pb_ 15_2017.pdf

8 World Health Organization, Unicef, World Bank. Nurturing care for early childhood development: a framework for helping children survive and thrive to transform health and human potential. 2018. http://www.who.int/maternal child adolescent/documents/nurturingcare-early-childhood-development/en/

9 Bauer U, Bittlingmayer UH. Wer profitiert von Elternbildung?Z Soziologie Erziehung Socialisation 2005;25:263-80.

10 Loytved C. Qualitätsbericht 2016. Außerklinische Geburtshilfe in Deutschland [Quality Report 2016. Outpatient Obstetrics in Germany]. QUAG e.V, 2017.

11 Thaiss HM, Burchardt S. Früherkennungsuntersuchungen im Spannungsfeld zwischen Kinderschutz und Gesundheitsförderung. In: Datenreport Frühe Hilfen. [Screening examinations in the area of conflict between child protection and health promotion.] NZFH, 2013: S28-35

$12 \mathrm{PMNCH}$. Methods guide for country case studies on successful collaboration across sectors for health and sustainable development. 2018. http://www.who.int/pmnch/ knowledge/case-study-methods-guide.pdf.

13 Helming E, Sandmeir G, Sann A, Walter M. Kurzevaluation von Programmen zu Frühen Hilfen für Eltern und Kinder und sozialen Frühwarnsystemen in den Bundesländern. Abschlussbericht. [Short evaluation of $\mathrm{ECl}$ programmes for parents and children and social early warning systems in the federal states. Final report] Deutsches Jugendinstitut, 2006. [German], https://www.bmfsfj.de/blob/90514/d0775c76244ceb51a31273b04a41516d/ evaluation-fruehe-hilfen-kurzbericht-data.pdf

14 Renner I, Heimeshoff V. Pilot projects in the German Federal States. Summary of results. National Centre for Early Prevention (NZFH), 2011. https://www.fruehehilfen.de/fileadmin/ user_upload/fruehehilfen.de/pdf/NZFH_Pilotprojekte_ENG_09_11.pdf

15 Eickhorst A, Schreier A, Brand C, etal . Inanspruchnahme von Angeboten der Frühen Hilfen und darüber hinaus durch psychosozial belastete Eltern. [Utilization of $\mathrm{ECl}$ offers and beyond by psychosocially burdened parents.]Bundesgesundheitsb/2016;59:1271-80 10.1007/s00103-016-2422-8

16 Windham AM, Rosenberg L, Fuddy L, McFarlane E, Sia C, Duggan AK. Risk of mother-reported child abuse in the first 3 years of life. Child Abuse Negl 2004;28:645-67. 10.1016/j.chiabu.2004.01.003 15193853
17 Sidebotham P, Heron JALSPAC Study Team. Child maltreatment in the "children of the nineties": a cohort study of risk factors. Child Abuse Negl 2006;30:497-522.

10.1016/..chiabu.2005.11.005 16701895

18 Stith SM, Liu T, Davies LC, etal . Risk factors in child maltreatment: a meta-analytic review of the literature. Aggress Violent Behav 2009;14:13-29. 10.1016/j.avb.2006.03.006

19 Olds DL, Sadler L, Kitzman H. Programs for parents of infants and toddlers: recent evidence from randomized trials. J Child Psychol Psychiatry 2007;48:355-91. 10.1111/1.1469-7610.2006.01702.x 17355402

20 Erickson MF, Egeland B. Die Staerkung der Eltern-Kind-Bindung. Frühe Hilfen für die Arbeit mit Eltern von der Schwangerschaft bis zum zweiten Lebensjahr des Kindes durch das STEEPTM - Programm. 2nd ed. Klett-Cotta, 2009.

21 Suess GJ, Bohlen U, Carlson EA, Spangler G, Frumentia Maier M. Effectiveness of attachment based STEEPTM intervention in a German high-risk sample. Attach Hum Dev 2016;18:443-60. 10.1080/14616734.2016.1165265 27035267

22 Suess GJ, Erickson MF, Egeland B, Scheuerer-Englisch H, Hartmann HP. STEEP ${ }^{T M}$. Steps toward effective, enjoyable parenting - lessons from 30 years of implementation, adaptation, and evaluation. In: Steele H, Steele M, eds. Handbook of attachment-based interventions. Guilford Press, 2017:102-28.

23 Moore GF, Audrey S, Barker M, etal . Process evaluation of complex interventions: Medical Research Council guidance. BMJ 2015;350:h1258. 10.1136/bmj.h1258 25791983

24 Küster EU, Pabst C, Sann A. Kommunalbefragungen des NZFH. In: Kommunale Netzwerkstrukturen Frühe Hilfen. Faktenblatt 3 zu den Kommunalbefragungen zum Aufund Ausbau der Frühen Hilfen. NZFH, 2017.

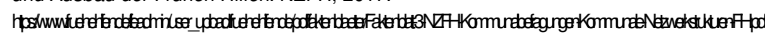

25 Küster EU, Pabst C, Sann A. Vernetzung der stationären medizinischen Versorgung mit den Frühen Hilfen. Faktenblatt 5 zu den Kommunalbefragungen zum Auf- und Ausbau der Frühen Hilfen. NZFH, 2017. https://www.fruehehilfen.de/fileadmin/user upload/ fruehehilfen.de/pdf/faktenblaetter/Faktenblatt-5-NZFH-Kommunalbefragungen-Vernetzungder-stationaeren-medizinischen-Versorgung-mit-den-FH.pdf.

26 Küster EU, Pabst C, Sann A. Vernetzung der ambulanten medizinischen Versorgung mit den Frühen Hilfen. Faktenblatt 4 zu den Kommunalbefragungen zum Auf- und Ausbau der Frühen Hilfen. NZFH, 2017. https://www.fruehehilfen.de/fileadmin/user_upload/ fruehehilfen.de/pdf/faktenblaetter/Faktenblatt-4-NZFH-Kommunalbefragungen-Vernetzungder-ambulanten-medizinischen-Versorgung-mit-den-FH.pdf.

27 Küster EU, Pabst C, Sann A. Einsatz von Gesundheitsfachkräften in den Frühen Hilfen. Faktenblatt 7 zu den Kommunalbefragungen zum Auf- und Ausbau der Frühen Hilfen. [German.] NZFH, 2017.

28 Renner I, Scharmanski S, Mechthild P. Ergebnisse der NZFH-Elternbefragung: Wie bewerten Mütter den Einsatz von Gesundheitsfachkräften in den Frühen Hilfen? Faktenblatt 2 zur Einschätzung von Effektivität und Nutzen der Angebote in den Frühen Hilfen. NZFH, 2017. https://www.fruehehilfen.de/fileadmin/user_upload/fruehehilfen.de/pdf/faktenblaetter/ Faktenblatt-2-NZFH-Effektivitaet-und-Nutzen-Elternbefragung.pdf.

29 Benz M, Sidor A. Early intervention in Germany and in the USA: A comparison of supporting health services. An overview article. Ment Health Prev 2013;1:44-5010.1016/..mhp.2013.10.004

30 Renner I, Heimeshoff V. Pilot projects in the German Federal States. Summary of results. National Centre for Early Prevention, 2011. https://www.fruehehilfen.de/fileadmin/user upload/fruehehilfen.de/pdf/NZFH_Pilotprojekte_ENG_09_11.pdf.

31 Sidor A, Kunz E, Eickhorst A, Cierpka M. Effects of the early prevention program "Keiner fällt durchs Netz" ("Nobody slips through the net") on child, mother, and their relationship. A controlled study. Infant Ment Health J 2013;34:11-2410.1002/imhi.21362

32 Jungmann T, Kurtz V, Brand T. Entwicklungsförderung im Rahmen Früher Hilfen vorläufige Befunde aus dem Modellprojekt „Pro Kind“ [German]. Verhaltensther Psychosoz Prax 2011;43:291-302

33 Renner I, Scharmanski S. Gesundheitsfachkräfte in den Frühen Hilfen. Hat sich ihr Einsatz bewährt? [Family midwives and nurses in early childhood intervention : Have they been successful?]Bundesgesundheitsb/ 2016:59:1323-31. 10.1007/s00103-016-2430-8

34 Advisory Board of the National Centre on Early Prevention. Working group on guiding principles. NZFH, 2014. https://www.fruehehilfen.de/fileadmin/user_upload/fruehehilfen. de/pdf/Publikation_NZFH_Kompakt_Beirat_Leitbild_fuer_Fruehe_Hilfen.pdf.

35 Fegert JM, Martens R, Wiebels K, Kölch M. Evaluation des Bundeskinderschutzgesetzes, Forum für Kinder- und Jugendpsychiatrie, Psychosomatik und Psychotherapie 3/2015:21-41. [German.] https://www.kinderpsychiater.org/fileadmin/downloads/forum/ 2015/forum 3 2015.pdf\#page $=21$.

36 Siebolds M, Münzel B, Müller R, Häußermann S, Paul M, Kahl C. Flächendeckende Implementierung von hilfesystemübergreifenden Qualitätszirkeln zum Thema Frühe Hilfen in Baden-Württemberg. Bundesgesundheitsb/2016;59:1310-410.1007/s00103-016-2427-3

37 Renner I, Scharmanski S, van Staa J, Neumann A, Paul M. Gesundheit und Frühe Hilfen: Die intersektorale Kooperation im Blick der Forschung[The health sector and early childhood Intervention: Intersectoral cooperation in research]. Bundesgesundheitsb 2018:61:1225-23510.1007/s00103-018-2805-0

38 Renner I. Zugangswege zu hoch belasteten Familien über ausgewählte Akteure des Gesundheitssystems. Ergebnisse einer explorativen Befragung von Modellprojekten Früher Hilfen[Access to high-risk families through selected actors in the health care system. Results of an explorative questioning of early childhood intervention pilot projects] Bundesgesundheitsb/ 2010;53:1048-5510.1007/s00103-010-1130-z.

39 Pelletier D, Gervais S, Hafeez-Ur-Rehman H, Sanou D, Tumwine J. Boundary-spanning actors in complex adaptive governance systems: The case of multisectoral nutrition. Int $J$ Health Plann Manage 2018;33:e293-319. . 10.1002/hpm.2468 29024002

Published by the BMJ Publishing Group Limited. For permission to use (where not already granted under a licence) please go to http://group.bmj.com/group/rights-licensing/ permissionsThis is an Open Access article distributed under the terms of the Creative Commons Attribution IGO License (https://creativecommons.org/licenses/by-nc/3.0/igo/), which permits use, distribution, and reproduction for non-commercial purposes in any medium, provided the original work is properly cited. 


\section{Table}

Table 1| Progress towards implementing cross sectoral networks and ECl measures, in 2015

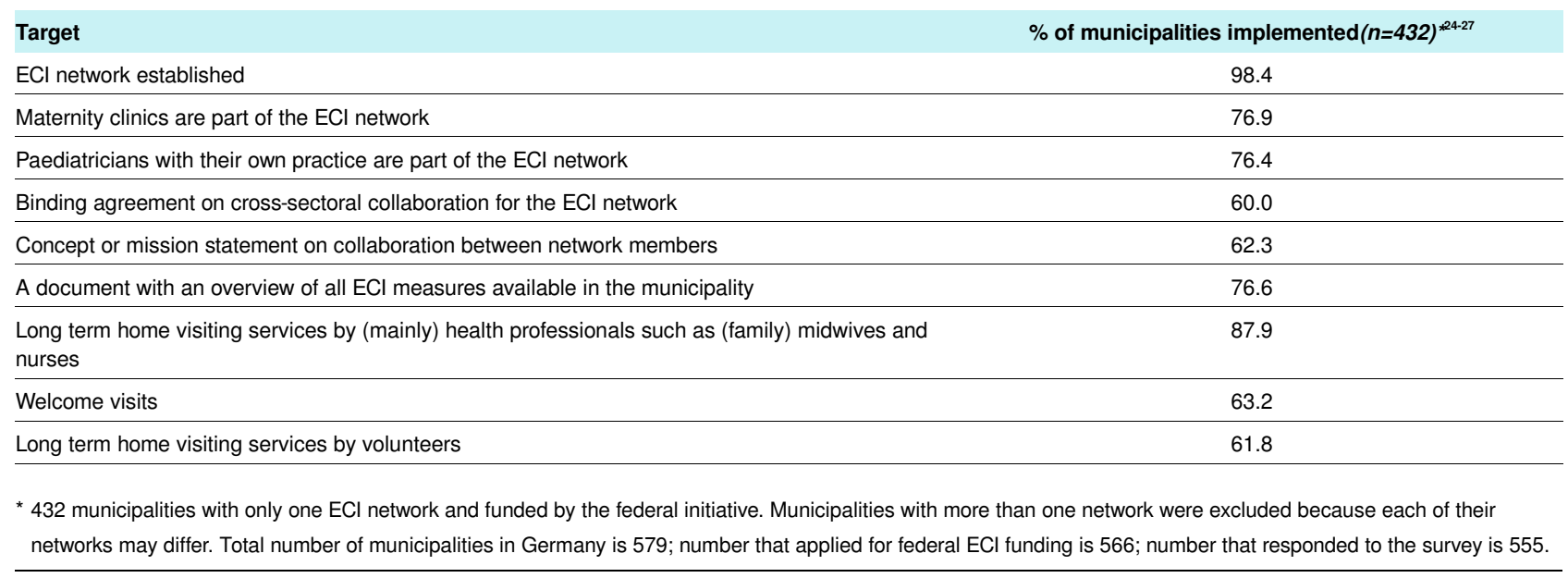




\section{Figure}

\section{Programme pilot phase} 2009-11

\section{Annual budget: $€ 11 \mathrm{~m}$}

Since 2006: 10 pilot projects located in all 16 federal states. These projects received additional funding from each federal state

2007: Establishment of NZFH as the federal coordinating agency for $\mathrm{ECl}$ with a clear mandate to progressively design, pilot, and scale-up the national ECI programme. NZFH coordinates scientific monitoring of 10 pilots projects

2011: Discussion, interpretation, and publication of results from pilot projects*
Programme scale-up and implementation phase 2012-17

1 January 2012: The Federal Child Protection Act came into effect, which includes the Federal Initiative for Early Childhood Intervention

\section{Annual budget: $€ 51 \mathrm{~m}$}

2012-17: Implementation of the Federal Initiative for Early Childhood Intervention, including establishment of cross-sectoral municipal networks and $\mathrm{ECl}$ measures - Effectively run to test programme and funding architecture to inform the design of the Federal Foundation for Early Childhood Intervention

- NZFH research framework further developed and evaulation of the progress of $\mathrm{ECl}$ fostered by the funding architecture undertaken

\section{Programme consolidation phase}

\section{8 onwards}

1 January 2018: Establishment of the Federal Foundation for Early Childhood Intervention, representing an evolution into a mandatory national programme under the Federal Child Protection Act

Annual budget: $€ 51 \mathrm{~m}$ provided (since 2006 ) by the Federal Ministry for Family Affairs, Senior Citizens, Women and Youth. Federal state and municipal authorities allocate additional resources for $\mathrm{ECI}$ measures

The Federal Foundation permanently secures annual financial resources and funding architecture dedicated to ensure $\mathrm{ECl}$

cross-sectoral networks and measures at the municipal level

*E.g. see: Renner I, Heimeshoff V. Pilot projects in the German Federal States. Summary of results. Cologne: National Centre for Early Prevention (NZFH) within the Federal Centre for Health Education; 2011. Available: https://www.fruehehilfen.de/fileadmin/user_upload/fruehehilfen.de/pdf/NZFH_Pilotprojekte_ENG_09_11.pdf

Fig 1 Timeline for Germany's ECI programme 